\title{
La prensa y la radio dibujadas por niños durante la Guerra Civil española (1936-1939) ${ }^{1}$
}

\author{
Jorge GALLARDO CAMACHO \\ Universidad Camilo José Cela \\ jgallardo@ucjc.edu \\ José Antonio Gallardo CRUZ \\ Universidad de Málaga \\ jagallardo@uma.es \\ Nerea VAdillo BengOA \\ Universidad de San Jorge \\ nvadillo@usj.es
}

Recibido: 28 de diciembre de 2013

Aceptado: 2 de abril de 2014

\section{Resumen}

Esta investigación analiza la presencia de la prensa y la radio en los dibujos realizados por los niños españoles durante la Guerra Civil española. Después de analizar 2.449 dibujos, hemos encontrado una muestra de cinco. Se ha utilizado una metodología descriptiva, en la que hemos tenido en cuenta el aspecto historiográfico, artístico y psicológico. Con este estudio aportamos una visión novedosa de la mirada infantil de la guerra y los medios de comunicación. Los niños incorporaron en sus dibujos escenas en las que se hicieron visibles la prensa de trinchera, la prensa empresarial, la prensa de partido político y el influjo de la música emitida por la radio.

Palabras clave: Guerra Civil, prensa, radio, dibujo infantil, medios de comunicación.

\section{The Press and the Radio as Drawn by Children during the Spanish Civil War (1936-1939)}

\begin{abstract}
This study investigates the representation of the press and the radio in children's drawings during the Spanish Civil War. After analysing 2,449 drawings, we found a sample of five. We used a descriptive methodology where we have taken into account the historiographical, artistic and psychological aspects. Therefore, in this research, we provide a new vision of the children's look of the war and media. The children drew scenes where appeared the trench press, the business press, the press of political party and the influence of music broadcasted on the radio.

Keywords: Spanish Civil War, press, radio, children's drawings, media.

\section{Referencia normalizada}

GALLARDO CAMACHO, Jorge; GALLARDO CRUZ, José Antonio; y VADILLO BENGOA, Nerea (2014): "La prensa y la radio dibujadas por niños durante la Guerra Civil española (1936-1939)". Estudios sobre el Mensaje Periodístico. Vol. 20, Núm. 2 (julio-diciembre), págs.: 1063-1080. Madrid, Servicio de Publicaciones de la Universidad Complutense.
\end{abstract}

Sumario: 1. Introducción. 2. Material y método. 3. Resultados y discusión; 3.1 Prensa de trinchera; 3.2. Prensa empresarial; 3.3. Prensa de Partido; 3.4. Radio. 4. Conclusiones. 5. Referencias bibliográficas.

1 Investigación realizada por el "Grupo de Investigación en Educomunicación GIEC (S82)"; reconocido como "grupo emergente" por el Gobierno de Aragón. Cofinanciado por Gobierno de Aragón y Fondo Social Europeo, "Construyendo Europa desde Aragón" 


\section{Introducción}

El 18 de julio de 1936, cuando los niños disfrutaban de sus vacaciones veraniegas, comienza la Guerra Civil española por la sublevación de una parte del ejército contra el gobierno legítimo de la República. Al fracasar las primeras negociaciones, España se divide en dos bandos, el franquista y el republicano, y la contienda se prolonga hasta el 1 de abril de 1939 con la victoria de Franco, que alargó su gobierno dictatorial hasta su muerte en 1975.

Debido a la mayor intensidad y frecuencia de los bombardeos, y a las continuas ofensivas exitosas del ejército franquista, la República perdía terreno y tuvo que diseñar un protocolo de evacuaciones para salvaguardar la vida de los niños. Muchos de ellos fueron trasladados a colonias escolares situadas en el centro y en la vertiente mediterránea, principalmente (Madrid, Cuenca, Albacete, Murcia, Levante, Cataluña, etc.) y otros fueron acogidos en otros países, como Francia, Unión Soviética, Bélgica, Reino Unido, etc. Una vez instalados y diagnosticados médicamente, vivieron, estudiaron, jugaron, cantaron y dibujaron (Sierra, 2009).

En algunas ocasiones, dibujaron con tanta exactitud la realidad bélica, que muchos dibujos se convirtieron en fotografías mentales reflejadas en un frágil papel, arrancado del cuaderno escolar, que hoy tiene más de setenta y cinco años de antigüedad.

La Guerra Civil española, que se transformó en un antecedente de la Segunda Guerra Mundial en los aspectos político, ideológico, militar y propagandístico, se convirtió en la primera contienda que fue seguida día a día por los corresponsales de guerra llegados de todo el mundo (de las Heras, 2009).

Tanto en la zona republicana como en la franquista, aquellos periódicos que manifestaron una ideología diferente fueron incautados y sus talleres aprovechados para diseñar otros afines. Todos ellos experimentaron una férrea censura cuando informaban de los frentes de combate (Álvarez \& Fernández, 2009; González, 1996). Mientras que en la zona franquista solo existió un modelo de prensa, que sobredimensionaba sus éxitos, en el sector republicano coexistieron diversas líneas periodísticas, que potenciaron los principios ideológicos de los republicanos, comunistas, anarquistas, libertarios y socialistas. Esta diversificación fomentó la coexistencia de la prensa de trinchera, prensa empresarial y prensa de partido.

Durante la contienda, la prensa de trinchera (Fernández, 1990; Núñez, 1992; Peláez \& Oliver, 1996; Pizarroso, 2005), publicada por las distintas unidades militares, dio cohesión estructural y política a los ejércitos de ambos bandos. Incluso mejoró la moral de combate, extirpando el derrotismo, consiguiendo el adoctrinamiento político e ideológico y contribuyendo a las campañas de alfabetización. En definitiva, esta prensa, editada precariamente en ocasiones, cumplía el objetivo de mantener informado al combatiente en el frente. Entre las republicanas citamos Vanguardia, Milicia Popular, La Voz del Combatiente, Obreros y Soldados, y entre las franquistas, La Ametralladora, El Soldado Español, Tarea.

La prensa empresarial estuvo representada por diarios populares de gran circulación, sostenidos por sociedades anónimas, cuya rentabilidad económica dependía de la tirada, del número de ejemplares vendidos y de la publicidad. Y aunque esta prensa se autocalificaba independiente, gozaba de matices ideológicos partidistas. Si nos ate- 
nemos a Madrid (Checa, 1989; Seoane \& Saiz, 1998) existió, antes de la conflagración, gran número de publicaciones; entre ellas, destacamos las tradicionalistas ( $E l$ Siglo Futuro), las monárquicas (ABC, La Época, La Nación, El Mundo, etc.), las republicanas independientes ( $\mathrm{La} \mathrm{Voz}$, Ahora, El Sol, etc.), las republicanas de izquierda (El Liberal, Heraldo de Madrid, Luz, La Libertad, etc.) y las de la Confederación Española de Derechas Autónomas (El Debate, Ya, Informaciones).

Durante el transcurso de la guerra e incluso en su recta final, los periódicos de las ciudades conquistadas por los franquistas fueron asaltados, sus trabajadores encarcelados y sus talleres precintados; en este contexto, Falange Española (González, 1990) tomó el control de un amplio grupo de empresas periodísticas, asentadas por toda la zona nacional, como Arriba, ABC sevillano, Arriba España, etc.

En la zona republicana, la prensa de partido político, llamada prensa de opinión, defensora de un partido o líder político (Seoane \& Saiz, 1998), sufrió penurias económicas, sobretodo durante la contienda que originó una menor tirada y un menor número de páginas; estos periódicos contribuyeron a la formación de una conciencia de base, pues se leían las noticias con gran atención y se difundían a gran velocidad mediante lecturas colectivas o pasando de manos en las tabernas, Casas del Pueblo, etc. Entre las cabeceras más conocidas citamos El Socialista, Mundo Obrero, Solidaridad Obrera, etc. En cambio, en la parte franquista, con un solo partido político integrado por falangistas y carlistas, se publicaron boletines, como el Boletín Oficial de Falange (González, 1990).

Como la elaboración de la prensa escrita era más costosa, laboriosa, lenta y, en muchos casos, de pago, no es de extrañar que durante la Guerra Civil la influencia de este medio disminuyera a favor del gran impacto de las ondas. Con la radio se transmitían la palabra y música, y era el medio de comunicación idóneo para ser utilizado en el conflicto bélico, pues moldeó las necesidades de la contienda en los dos bandos (Garitaonaindía, 1988).

Al estallar la conflagración, las emisoras de radio fueron incautadas por el bando correspondiente. Entre las republicanas citamos Unión Radio (Madrid, Barcelona y Valencia), Radio España, Trans-Radio, etc., y entre las franquistas, Radio Las Palmas, Unión Radio Sevilla, Radio Club Tenerife, Radio Ceuta, Radio Tetuán y Radio Melilla, etc., que siguieron el ejemplo de la radiodifusión italiana (EIAR, Ente Italiano per le Audizione Radiofoniche) y alemana (RRG, Rundfunk Reichs Gessellschaft); por ejemplo, Alemania contribuyó al nacimiento de Radio Nacional, embrión de la actual cadena radiofónica española, instalando una potente emisora de la marca Lorenz, con una potencia de 10 kilovatios (Cervera, 1998; Pizarroso, 1990, 2005; Ventín, 1984).

La radio jugó su papel en ambas direcciones cuando se difundían partes de guerra y música (Cervera, 1998; Zaragoza, 2007); eso supuso que, a excepción de las canciones patrióticas y de los himnos militares, compartieron otras melodías que les ayudaron a olvidar la guerra; además, los republicanos conocieron con detalle sus derrotas, lo que minaba la moral en la retaguardia. Esto nos demuestra que la radio se convirtió en un arma de guerra que los franquistas supieron utilizar con mayor destreza; esta guerra radiofónica no pasó desapercibida en el extranjero y sirvió de entrenamiento para que los franceses, los británicos, los soviéticos, los alemanes y los italianos la aplicaran en la Segunda Guerra Mundial (Pizarroso, 2005; Ventín, 1984). 
Por tanto, la prensa y la radio se utilizaron en la contienda española, considerada por los historiadores, como la primera guerra moderna porque los civiles se transformaron en objetivo militar. Incluso se convirtió en un laboratorio de pruebas para contrastar los efectos devastadores de un armamento moderno, procedente de Alemania e Italia, que apoyaron a los franquistas, y de la Unión Soviética, que ayudó a la República (Beevor, 2011).

No hemos encontrado estudios previos que analicen los medios de comunicación dibujados por niños que sufrieron una conflagración bélica; sin embargo, existen dos trabajos que investigaron contextos diferentes: el ambiente musical (Gallardo \& Gallardo, 2011) y las evacuaciones infantiles multitudinarias (Gallardo, 2012). El objetivo de este trabajo consiste en analizar y correlacionar los medios de comunicación con las escenas dibujadas por los niños cuyos padres lucharon en ambos bandos.

\section{Material y método}

Desarrollaremos este estudio exclusivamente con los dibujos de los hijos de los republicanos, utilizando un análisis descriptivo. La ausencia de dibujos infantiles bélicos en el sector franquista se debió a tres causas (Gallardo, 2012): a) la infancia no necesitó ser evacuada ni internada en colonias alejadas de los frentes de combate; b) no hubo iniciativa ministerial para recoger este material dibujado; c) la República era la que retrocedía geográficamente debido a las potentes ofensivas franquistas y tuvo que salvaguardar la vida de la población civil, especialmente la de los niños.

Para extraer la muestra, hemos revisado los dibujos de las colecciones más importantes del mundo: 1.172 de la Biblioteca Nacional de España (Madrid), 617 de la Southworth Spanish Civil War Collection (Mandeville Special Collections Library, Universidad de California (San Diego), 153 de la Avery Architectural \& Fine Arts Library (Universidad de Columbia, Nueva York) y 507 del coleccionista español Ramón Soley Ceto. En total, el universo alcanzó 2.449 dibujos.

El hecho de que muchos de ellos se encuentren actualmente en instituciones norteamericanas se debió a fines recaudatorios y propagandísticos (Sierra, 2009). En 1938, por recomendación de la Spanish Child Welfare Association y de la American Friends Service Committee (los cuáqueros de Filadelfia), Joseph Anthony Weissberger regresó de la España republicana con cerca de mil dibujos; con parte de ellos diseñó una exposición en los almacenes Lord \& Taylor de la Quinta Avenida de Nueva York y publicó un libro (Weissberger, 1938), que se vendió a un dólar. Tuvo tanto éxito el evento que se exhibió en otras ciudades estadounidenses y en Reino Unido. Todo el dinero recaudado se donó a la República.

Para desarrollar este análisis tendremos en cuenta tres métodos: a) el historiográfico, con el que correlacionaremos las publicaciones relacionadas con la contienda española y con los medios de comunicación (Checa, 1989; de la Ossa, 2011; Garitaonaindía, 1988; Núñez, 1992; Seoane y Saiz, 1998; Nash, 1999); b) el artístico, con el que analizaremos la técnica y el realismo visual (Euwema, De Graaff, De Jager \& Kalksma-Van Lith, 2008; López, San Pedro \& López, 1997; Machón, 2009; Veale, 2005); c) el psicológico, con el que conseguiremos una visión global, integradora y totalizadora de la escena dibujada (Brauner, 1946; Veale, 2005). 


\section{Resultados y discusión}

El hecho de presentar simultáneamente los resultados con la discusión se debe al análisis intrínseco de los dibujos. Al estudiar los dibujos infantiles, resulta más operativo relacionar individualmente cada escena dibujada con la información publicada, lo que validaría las argumentaciones derivadas de los elementos dibujados.

Después de revisar 2.449 dibujos, obtuvimos una muestra de cinco dibujos no fechados. No obstante, cada una de las instituciones que los custodian admiten que fueron hechos alrededor de 1937. En la Tabla 1 aparecen los datos personales, los medios de comunicación dibujados, las instituciones escolares donde realizaron los dibujos y su ubicación.

Tres dibujos están coloreados y dos están hechos con lapicero de grafito. Tres niños (Figuras 3, 4 y 6) escribieron la información en el anverso y dos (Figuras 1 y 2) en el reverso para explicar la escena dibujada. Cuatro dibujos (Figuras 1, 2, 3 y 6) proceden de colonias alejadas de los frentes: uno se realizó en Bayonne y otro en Cerbère, localidades francesas próximas a la frontera española; y los dos restantes, en Murcia y en Valencia, ciudades republicanas de la zona mediterránea. En cambio, otro (Figura 4), por la información existente en el sello de caucho, proviene de un centro escolar enclavado en la calle General Oráa número 49 de Madrid, ciudad que sufría el fuego continuado de la artillería pesada y los bombardeos aéreos franquistas; a pesar de ello, por las fotografías de Díaz Casariego publicadas en la página 11 del diario $A B C$ madrileño de 18 de agosto de 1937, hemos comprobado que este centro todavía impartía clases con total normalidad, posiblemente esperando que sus alumnos fueran evacuados a colonias instaladas en otras ciudades alejadas de la espiral de la guerra.

\begin{tabular}{|c|c|c|c|c|}
\hline $\begin{array}{l}\text { Figuras y autores de los } \\
\text { dibujos }\end{array}$ & Edad & Medios & Instituciones escolares & Ubicación actual del dibujo \\
\hline $\begin{array}{l}\text { Figura } 1 \\
\text { Inés Millán Romeo } \\
\text { (de Bilbao) }\end{array}$ & $\begin{array}{l}13 \\
\text { años }\end{array}$ & Prensa & $\begin{array}{l}\text { Colonia en Bayonne } \\
\text { (Francia) }\end{array}$ & $\begin{array}{l}\text { Biblioteca Nacional de } \\
\text { España (Madrid) }\end{array}$ \\
\hline $\begin{array}{l}\text { Figura } 2 \\
\text { Magdalena García } \\
\text { Hernández }\end{array}$ & $\begin{array}{l}11 \\
\text { años }\end{array}$ & Prensa & $\begin{array}{l}\text { Centro Español en } \\
\text { Cerbère (Francia) }\end{array}$ & $\begin{array}{l}\text { Biblioteca Nacional de } \\
\text { España (Madrid) }\end{array}$ \\
\hline $\begin{array}{l}\text { Figura } 3 \\
\text { Victoriano Cepeda Acosta }\end{array}$ & $\begin{array}{l}13 \\
\text { años }\end{array}$ & $\begin{array}{l}\text { Prensa } \\
\text { El Liberal }\end{array}$ & $\begin{array}{l}\text { Guardería Infantil de } \\
\text { Guerra Trabajadores de } \\
\text { la Enseñanza (UGT) en } \\
\text { Colonia Lobosillo } \\
\text { (Murcia) }\end{array}$ & $\begin{array}{l}\text { Avery Architectural \& Fine } \\
\text { Arts Library. Columbia } \\
\text { University Libraries (Nueva } \\
\text { York) }\end{array}$ \\
\hline $\begin{array}{l}\text { Figura } 4 \\
\text { Tomás Pérez }\end{array}$ & $\begin{array}{l}10 \\
\text { años }\end{array}$ & $\begin{array}{l}\text { Prensa } \\
\text { El Socialista }\end{array}$ & $\begin{array}{l}\text { Grupo Escolar General } \\
\text { Oráa (Madrid) }\end{array}$ & $\begin{array}{l}\text { Colección particular de } \\
\text { Ramón Soley Ceto }\end{array}$ \\
\hline $\begin{array}{l}\text { Figura } 6 \\
\text { María Antolín }\end{array}$ & - & Radio & $\begin{array}{l}\text { Comunidades familiares } \\
\text { de Educación en El } \\
\text { Perelló (Valencia) }\end{array}$ & $\begin{array}{l}\text { Avery Architectural \& Fine } \\
\text { Arts Library. Columbia } \\
\text { University Libraries (Nueva } \\
\text { York) }\end{array}$ \\
\hline
\end{tabular}

Si relacionamos los 2.449 dibujos con los cinco de la muestra, solo el $0.2 \%$ representa dos medios de comunicación (prensa y radio). Y si este porcentaje es tan bajo se debe a que la mayoría de niños dibujaron elementos relacionados con la guerra, 
como bombardeos, evacuaciones, racionamiento, casas derruidas, etc. (Brauner, 1946). Al examinar los dibujos, hemos identificado cuatro de ellos relacionados con la prensa (prensa de trinchera, empresarial y de partido político) y uno, con la radiodifusión de noticiarios de guerra o de programas musicales.

\subsection{Prensa de trinchera}

Inés (Figura 1), nacida en Bilbao, reproduce el frente Norte por la zona de Bilbao, ciudad conquistada por los franquistas el 19 de junio de 1937 (Beevor, 2011). En el reverso escribe:

"En esta escena se representa el frente, en el cual se ve unos cuantos milicianos enterándose de las noticias del periódico. Algunos milicianos comiendo; otros fumando y una enfermera sacando la camilla para limpiar el coche de la ambulancia".

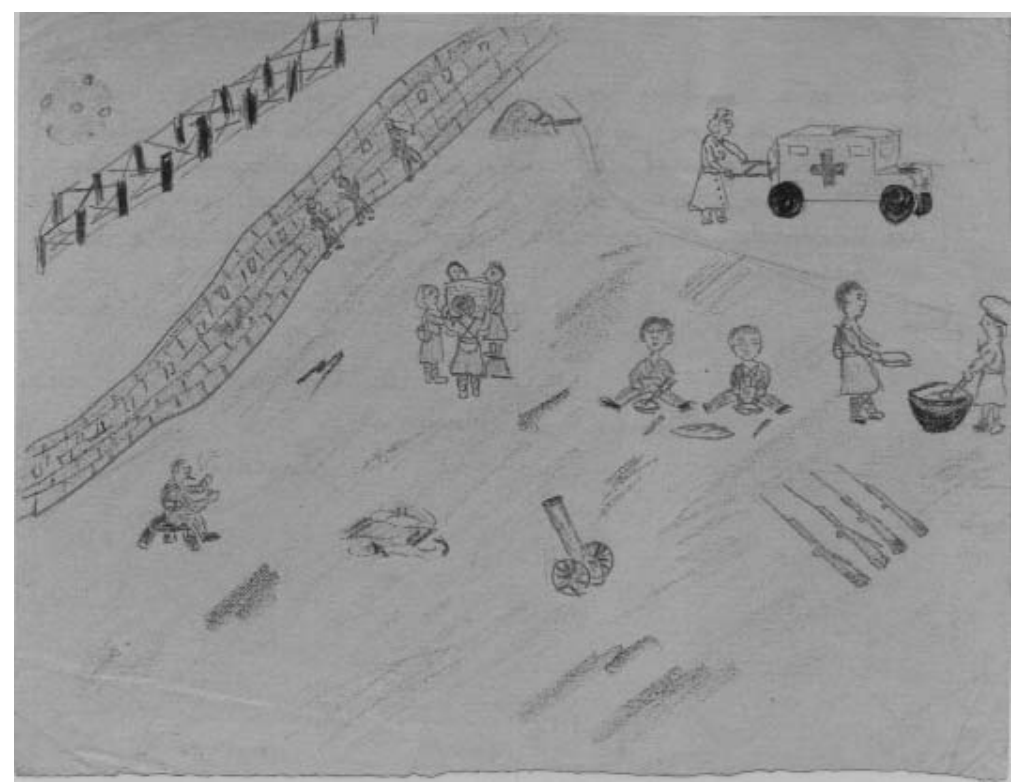

Figura 1. Inés Millán Romero, 13 años. Biblioteca Nacional de España (Madrid)

(Signatura: DIB/19/1/876)

En la parte central del dibujo aparece una miliciana leyendo en voz alta a sus compañeras las noticias de la prensa, lo que indicaría la existencia de un alto nivel de analfabetismo; por eso mismo, en 1937 estaba previsto abrir dos mil escuelas militares para que cien mil milicianos dejaran de ser analfabetos (Thomas, 1976). Como el frente Norte no estuvo unido geográficamente al resto de la España republicana, eran muy escasas las posibilidades de que el periódico dibujado por Inés procediera, según Checa (1989) y Seoane \& Saiz (1998), de Madrid (Ahora, Heraldo de Madrid, El Liberal, Mundo Obrero, El Socialista, La Voz, Sol, etc.), de Barcelona (El Diluvio, La Noche, Solidaridad Obrera, etc.) o de Valencia (El Pueblo, etc.). Por este motivo, presuponemos que se trata de un periódico bilbaíno con una aceptable difusión. 
Si analizamos la información de estas dos últimas publicaciones, creemos que podrían ser: a) el diario matutino Euzkadi (primer número 1913-cierre 1937) o el diario vespertino La Tarde (1914-1937), que representaron la línea oficial, católica y derechista del Partido Nacionalista Vasco; b) El Liberal de Bilbao, que fue un diario matutino con tintes liberales republicanos y con tendencias próximas al PSOE (Partido Socialista Obrero Español).

Pero como Inés dibujó el frente bilbaíno, creemos que las noticias leídas proceden de un periódico de trinchera diseñado para el frente. Para identificarlo, seleccionaremos de las 454 publicaciones de guerra (Núñez, 1992), aquellas que cumplan los siguientes requisitos: a) han de estar publicadas antes de que se llevaran a cabo las evacuaciones marítimas de los niños, diseñadas por el gobierno vasco, durante los seis primeros meses de 1937 (Alonso, 1998); b) el equipo de impresión y de redacción han de estar instalados en Vizcaya o en localidades cercanas, como Guipúzcoa; c) tuvo que estar diseñada también para los milicianos; d) sus dimensiones tenían que ser iguales o superiores a un folio porque con ese tamaño lo dibujó la niña. Después de aplicar estas condiciones, la publicación que lee la miliciana es una de estas tres (Núñez, 1992):

- Alerta (órgano del batallón Karl Liebknecht), que se editó por primera vez en enero o febrero de 1937 en los Talleres Gráficos de Erandio (Bilbao,Vizcaya); tuvo una extensión de cuatro páginas a tres columnas por página y un formato de 31 x 22 centímetros, y se convirtió en uno de los boletines del Partido Comunista de Euskadi.

- Disciplina (semanario del órgano del batallón Rosa de Luxemburgo), que nació en enero de 1937 en los Talleres Gráficos Sabin, ubicados en Erandio (Bilbao,Vizcaya); tuvo cuatro páginas a tres columnas, con escasas ilustraciones y fue fundada por el Partido Comunista de Euskadi.

- Voz Miliciana (órgano del batallón Amuategui, tercero de la Columna Meabe), que apareció en 1936 en Éibar (Guipúzcoa); ciudad que cayó en poder de los franquistas el 26 de abril de 1937 (Gutiérrez, 2007), el mismo día que Guernica fue bombardeada y arrasada por la Legión Cóndor alemana y por la Aviación Legionaria italiana (Solé i Sabaté \& Villarroya, 2003). Esta publicación quincenal se editó con un tamaño variable ( 23 x 34.5 centímetros; 31 x 43.8 centímetros) y alcanzó una media de cuatro páginas a dos columnas; formó parte de las Milicias Marxistas y en él se difundieron los discursos de Santiago Carrillo.

La niña dibuja la escena en Bayonne (Francia) cuando fue evacuada por mar, desde Bilbao, en una de las expediciones vascas desarrolladas en 1937 (Alonso, 1998). Esta ciudad estuvo fortificada con un cinturón de hierro de 80 kilómetros de perímetro con fortificaciones de cemento y troneras (Beevor, 2011).

Al observar la escena, comprobamos que la dibujante incorpora esta larga fortificación al incluir una espesa y densa alambrada con gruesas vigas de hierro y un muro de albañilería con aspilleras para que los milicianos vigilen o abran fuego de fusilería. En la parte superior aparece un montículo de arena, con su pala, para indicar que con ese material se hacían los sacos térreos para reforzar el muro si recibía un im- 
pacto directo. Aunque retumbe por toda la escena la explosión dibujada en el extremo izquierdo, sabemos por el texto de la niña que era la hora del almuerzo.

Se advierte la presencia de una cocinera que sirve la ración a otra miliciana que le acerca su plato de aluminio. Ante la atenta mirada de un miliciano fumador, que descansa en un taburete, otros dos milicianos, sentados en el suelo, toman el rancho con cuchara y cuchillo, y comparten una barra de pan. Simultáneamente a esta acción, vemos cómo una enfermera extrae una camilla de la ambulancia para limpiarla, posiblemente, de sangre.

Inés dibuja a las milicianas con falda y a los milicianos con pantalón. Pero la realidad fue diferente, pues ellas lucieron el mono azul revolucionario portando un fusil. Desde el inicio de la contienda, la figura de la miliciana fue el símbolo de la movilización popular, pues evocaba el valor y el coraje del pueblo en su lucha contra el fascismo (Nash, 1999; Sedeño, 2007). Como muy acertadamente ha reflejado esta niña, las milicianas, en el frente, estuvieron la mayoría de ellas alejadas del uso de las armas y desempeñaron acciones auxiliares relacionadas en la época con el sexo femenino, como cocinar, lavar la ropa, ejercer de enfermeras, etc. (Piñeiro, 2007; Nash, 1999; Sedeño, 2007).

\subsection{Prensa empresarial}

Dentro de esta modalidad hemos localizado los dibujos de Magdalena (Figura 2) y Victoriano (Figura 3). La niña reproduce un ambiente hogareño y lo explica en el reverso:

"El dibujo representa mi casa mi mamá que barre y mi papá lee el diario mis hermanos juegan y la otra familia hacen la comida".

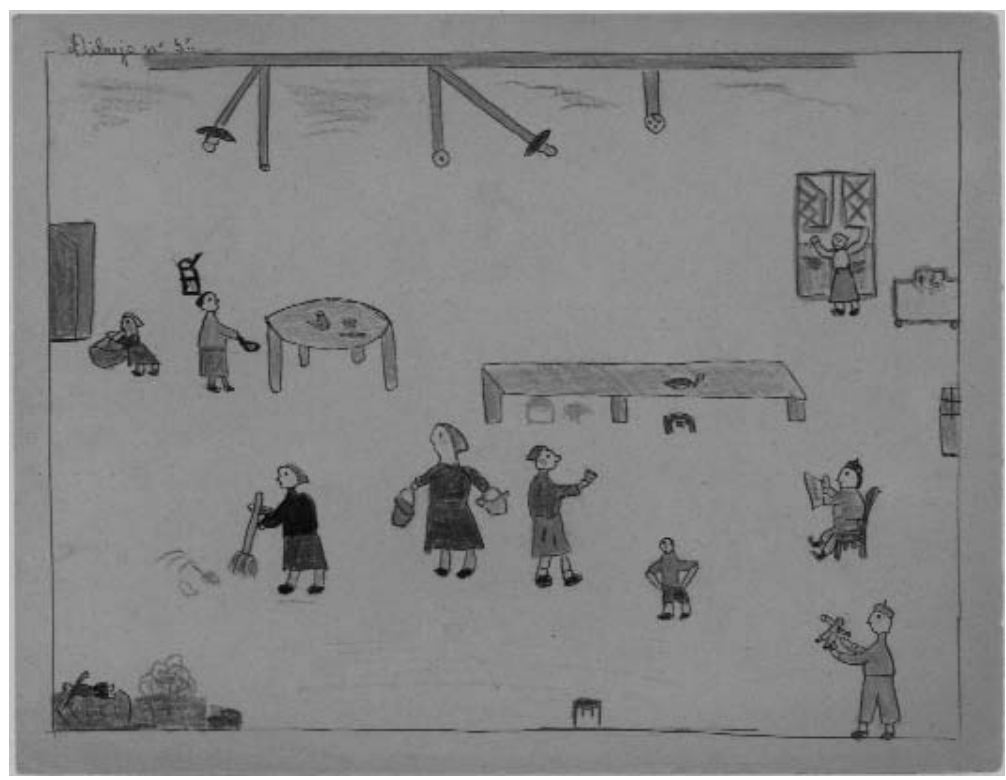

Figura 2. Magdalena García Hernández, 11 años. Biblioteca Nacional de España (Madrid) (Signatura: DIB/19/1/959) 
La escena se desarrolla en el comedor y parece que Magdalena es la niña, con falda roja, que se sitúa en el centro del dibujo llevando un vaso al padre. Al leer el texto deducimos que en esta casa vivía otra familia que había alquilado una o dos habitaciones, con derecho a cocina. Incorporó también lo que veía diariamente en su casa: la madre desempeñando las faenas del hogar y el padre, con boina, leyendo el periódico. Como la niña no anotó la ciudad en la que vivía ni la cabecera del periódico no podemos identificarlo. Este dibujo certifica que, en muchos hogares, las mujeres se responsabilizaron de las tareas hogareñas, aunque la legislación republicana mejoró su situación social (Nash, 1999). Otro detalle dibujado con precisión fue la instalación eléctrica que por aquellos años estaba instalada en la superficie de las paredes: hilos conductores trenzados y forrados de hilo de seda, enchufe e interruptores de baquelita y lámparas con visera.

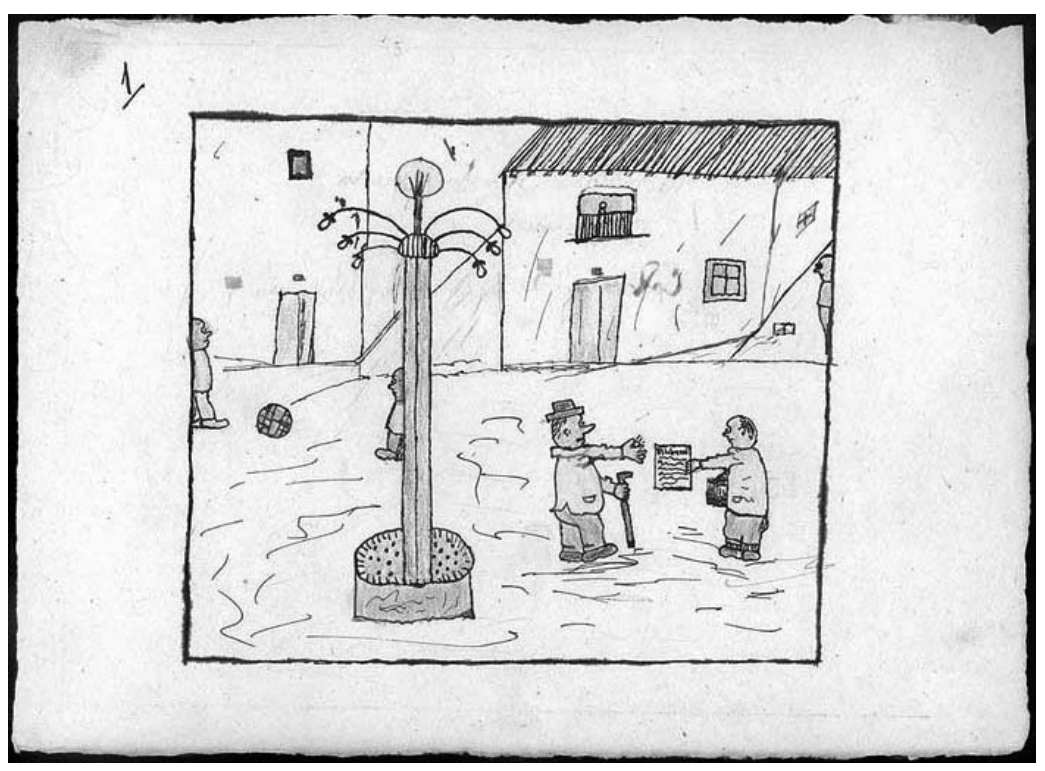

Figura 3. Victoriano Acosta Cepeda, 13 años. Texto: El Liberal. Avery Architectural \& Fine Arts Library. Columbia University Libraries (Nueva York) (Signatura: No. 25)

Por su parte, Victoriano dibujó un vendedor, que recorría las calles voceando las cabeceras de los periódicos y los titulares de sus portadas. El voceador está entregando un ejemplar de El Liberal a un viandante, que alarga su brazo derecho para entregarle 15 o 25 céntimos de peseta, precio estipulado a lo largo de la contienda. Esta transacción se desarrolla en una plaza en la que juegan dos niños a la pelota y en la que existe una farola con su alcorque cementado con guijarros de río.

Aunque El Liberal fue uno de los periódicos de mayor difusión durante la contienda, el hecho de que este niño escribiera su cabecera nos permite localizar, con reservas, la localidad. Este periódico matutino se imprimió en Madrid, Barcelona, Sevilla, Bilbao y Murcia (Checa, 1989). Descartamos Bilbao porque los niños vascos 
realizaron su evacuación por mar y fueron alojados en Francia (Cerbère, Bayonne, etc.); Sevilla no puede ser porque sus instalaciones fueron asaltadas en 1936 por falangistas, que incautaron el material de imprenta para publicar el diario $F E$, órgano de la Falange Española sevillana (Álvarez \& Fernández, 2009); Barcelona tampoco, porque las evacuaciones partieron de esta ciudad con dirección a Francia y porque se mantuvo vigente hasta 1936. La escena podría pertenecer a Madrid o a Murcia, porque en ambas ciudades, este periódico cerró sus puertas en 1939. Pero como Victoriano estuvo alojado en una localidad murciana (Tabla 1), sostenemos que El Liberal dibujado es el de Murcia.

Según González (1996), desde los primeros años del siglo XX, El Liberal murciano, creado en 1902 por Enrique Rivas Beltrán con claras actitudes republicanas, no se vendía exclusivamente por las calles de esta localidad. Tuvo la competencia del diario católico La Verdad, que se puso a la venta el 1 de marzo de 1903, y de $E l$ Tiempo, que fue fundado en 1908 con una trayectoria política independiente y conservadora.

Durante la Guerra Civil, El Liberal murciano se convirtió en el diario más difundido de la provincia, pero tuvo que coexistir, según González (1996), con: a) Nuestra Lucha (1936-1939), portavoz de la Unidad Obrera que manifestó una orientación socialista próxima al sindicato UGT (Unión General de Trabajadores) y se editó en los talleres incautados al diario La Verdad; b) Confederación (1937-1939), que fue el órgano principal de la CNT (Confederación Nacional del Trabajo), FAI (Federación Anarquista Ibérica) y FIJL (Federación Ibérica de las Juventudes Libertarias), cuya impresión se hizo en los talleres expropiados a El Tiempo; c) Unidad (1937-1939), que fue el portavoz del Partido Comunista y tuvo su sede también en las mismas instalaciones de Nuestra Lucha.

\subsection{Prensa de partido}

Tomás Pérez (Figura 4) reproduce un joven vocero vendiendo el diario El Socialista por las calles madrileñas al precio de 15 céntimos de peseta. Sabemos que la imagen dibujada refleja una estampa de Madrid porque el dibujo contiene el sello azulado del Ministerio de Instrucción Pública y el nombre del centro escolar que estuvo ubicado en la calle General Oráa.

Para difundir la venta de los diarios, se generalizó, desde los primeros años del siglo XX, la suscripción, pero este procedimiento de venta fue disminuyendo progresivamente a favor de la venta callejera (Seoane \& Saiz, 1998), tal como aparece en el dibujo. Esta estampa madrileña ha sido validada por el testimonio del niño de la guerra Pedro Castro Vizcaíno, con 88 años de edad, que todavía recuerda a los voceros madrileños, con blusón azul, pañuelo chulapo en el cuello, gorra y flequillo, anunciando por el barrio Las Vistillas, uno o dos años antes de la contienda, los diarios vespertinos de diferentes ideologías: ;La Voz! ¡El Heraldo! ;Informaciones! ; La Nación! ;La Tierra! ¡Luz!

Tomás incluye la cabecera de este diario con un tamaño parecido al que tenía originariamente ( 59 x 43 centímetros) durante los primeros compases de la guerra, y no con seis columnas, sino con tres. En la portada dibujada aparecen fragmentos de texto 
en blanco para señalar que fueron censurados. Hemos comprobado este hecho en la portada de El Socialista (Figura 5) donde era habitual colocar cajas en blanco en las tablas de impresión para indicar al lector que esas noticas habían sido censuradas. Conviene matizar que este dibujo presenta una madurez artística (perfección, volumen, simetría y proporción) que no es propia de un niño de 10 años de edad; por esto, creemos que el niño lo calcó o recibió ayuda del maestro.

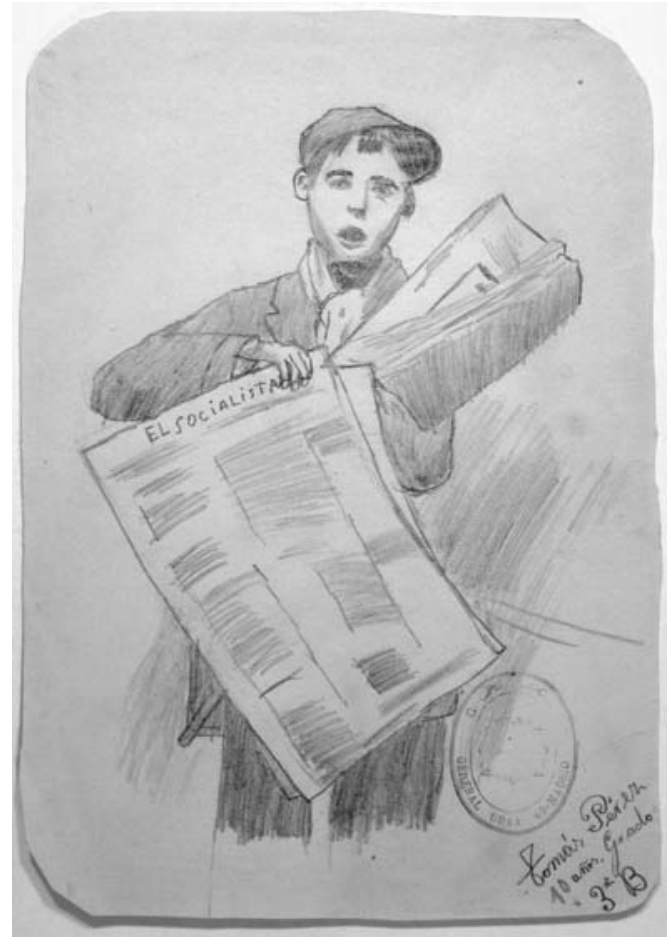

Figura 4. Tomás Pérez, 10 años. Colección particular de Ramón Soley Ceto

Por la cronología escrita por García (2011), el 12 de marzo de 1886, Pablo Iglesias fundó el diario madrileño El Socialista, órgano oficial del PSOE. Pasó a ser propiedad del partido, en agosto de 1890; para su sostenimiento se acordó la suscripción de los afiliados con una aportación mensual de 10 céntimos de peseta. El 31 de enero de 1896 apareció con el subtítulo: órgano central del Partido Obrero. Pasó a ser diario matutino el 1 de abril de 1913 y a partir del 1 de septiembre de 1914 salió por la tarde. A lo largo de su dilatada vida, El Socialista experimentó censura de noticias, cierres, secuestros de ejemplares en la calle y talleres, y denuncias gubernamentales que recayeron en Pablo Iglesias, Mariano García y Eduardo Torralva, por sus ácidos comentarios.

El 2 de mayo de 1938 apareció El Socialista en Barcelona. Durante la contienda, la edición madrileña de El Liberal fue irregular, por escasez de papel. El 28 de marzo de 1939 se publicó el último número: 9.042. Entre sus directores históricos destaca- 
mos a Pablo Iglesias y Julián Zugazagoitia. El régimen franquista incautó los talleres y se editó el Boletín Oficial del Estado. Con gran precariedad se publicó en Francia y clandestinamente en España hasta la llegada de la democracia. Hoy se publica digitalmente bajo la dirección de Joaquín Tagar (García, 2011).

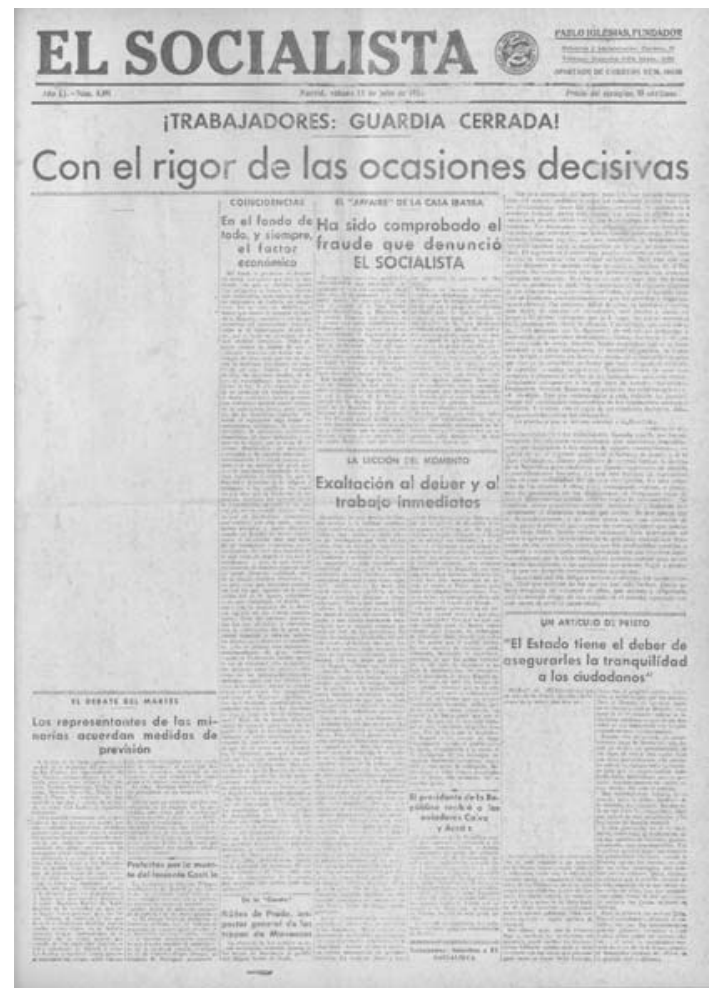

Figura 5. Portada de El Socialista. Madrid 18 de julio de 1936. Las noticias censuradas por el gobierno republicano aparecen en blanco. Ejemplar de la Fundación Pablo Iglesias. Alcalá de Henares, Madrid (Signatura: ES 1936-07-18 n-28191)

\subsection{Radio}

El hecho de que María Antolín (Figura 6) incluyera un radiorreceptor nos permite asegurar que este aparato se convirtió durante la Guerra Civil en uno de los medios más eficaces para mantener informados a los combatientes y a las retaguardias de los dos bandos en lucha. Las emisiones de radio se trasformaron en auténticas trincheras de combate en la lucha propagandística.

Los niños, cuando dibujan, tienden a incluir elementos por toda la superficie de la hoja y si María no lo hizo fue por influjo del maestro. La niña se limitó a reproducir de la pizarra el Noveno punto de la Declaración de Principios del Gobierno de la República española y lo adornó con una cenefa, una ventana, una estantería con flores y un cacto; también se le ocurrió incluir una chimenea azulejada con un botijo y un plato de cerámica, y una radio de la que fluye una melodía musical: 
"El Estado garantizará los derechos del trabajo a través de una legislación social avanzada, de acuerdo con las necesidades específicas de la vida y de la economía española”.

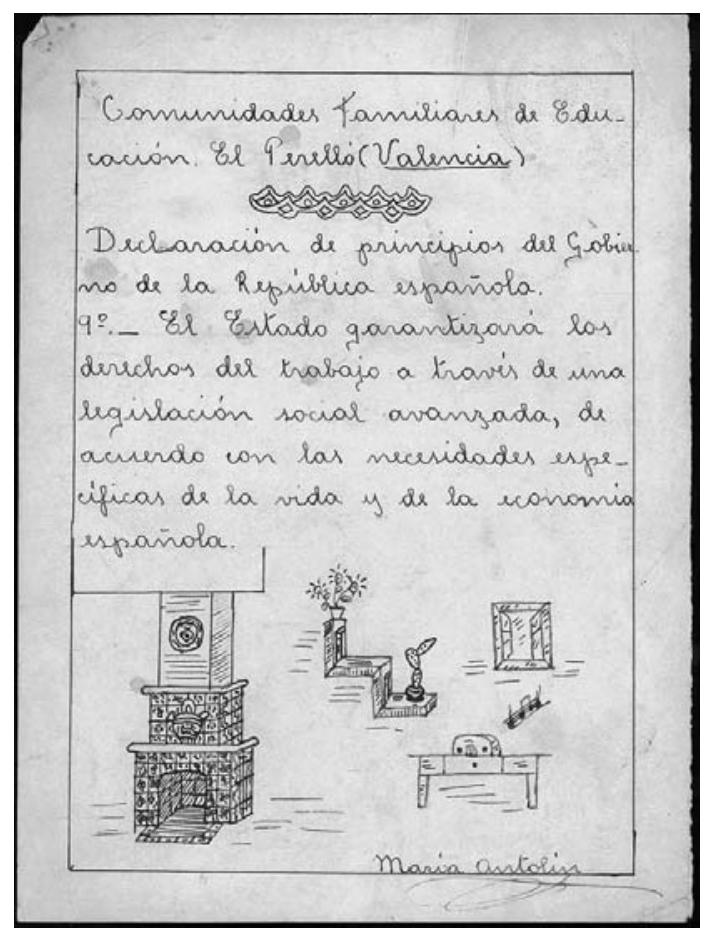

Figura 6. María Antolín. Avery Architectural \& Fine Arts Library. Columbia University Libraries (Nueva York) (Signatura: No. 153)

Pero como la radio dibujada por María no emitía palabras escritas, sino notas musicales, sostenemos que podría tratarse de:

a) Música publicitaria de diversos productos, como Caldos Gallina Blanca, Laboratorios Juanola, etc. (Herreros, 2007).

b) Música de guerra, como marchas, himnos militares y coplas bélicas (de la Ossa, 2011; Zaragoza, 2007), en la que cobró protagonismo Altavoz del Frente, organismo del PCE, cuya programación musical se propagaba a través de Unión Radio Madrid y de una potente red de megafonía fija o móvil, instalada en camionetas o camiones-altavoz; pero además de las radiodifusiones musicales, Altavoz del Frente también desarrolló otras actividades para entretener al combatiente: exposiciones, teatro, periódicos y propaganda (Peral, 2012). Con estas acciones se intentaba aminorar el impacto de la vida en las trincheras: suciedad, soledad, falta de sueño, temperaturas extremas, miedo, desconocimiento de la hora y día del próximo combate, muerte e invasión de moscas, de piojos, de chinches y de ratas (de la Ossa, 2011). 
c) Música culta, como óperas (Marina, La Dolores, Bohemios, etc.), zarzuelas (Gigantes y cabezudos, La Verbena de la Paloma, Doña Francisquita, etc.), ballets y sinfonías de los autores universales más representativos (de la Ossa, 2011).

d) Música folclórica, popular o tradicional recopilada por las Misiones Pedagógicas y utilizada en los centros escolares o en cualquier emisora potente (Otero \& García, 2006).

e) Música ligera bailable (coplas, pasodobles, tangos, etc.) cantada por las figuras del momento, como "Angelillo", Concha Piquer, Estrellita Castro, Imperio Argentina, Carlos Gardel, etc. (de la Ossa, 2011).

\section{Conclusiones}

Este estudio, realizado exclusivamente con dibujos de los hijos de los republicanos, abre una nueva línea de investigación con tintes históricos en las áreas de las Ciencias de la Comunicación y de la Educación, porque no hemos encontrado referencias nacionales ni internacionales que estudiaron los medios de comunicación dibujados durante cualquier contienda desarrollada a lo largo del siglo XX.

La tónica general de los 2.449 dibujos, observados para extraer la muestra, manifestó que muchos de los dibujantes incluyeron elementos relacionados con la guerra, con su vida cuando existía paz o con las colonias que le dieron refugio. Y si no dibujaron los periódicos y los temas radiofónicos fue debido a que: a) los maestros no les sugirieron el tema; b) no les llamó la atención, pues existían antes de la contienda; c) estaban diseñados especialmente para los adultos; d) no eran habitualmente leídos ni escuchados porque muchos de los niños no tenían nivel cognitivo apropiado para captar los mensajes políticos.

Sin embargo, cinco dibujantes plasmaron los medios de comunicación, y sus escenas se convirtieron en referentes de: a) la prensa de trinchera, que mantuvo al corriente a los combatientes; b) la prensa empresarial, que informó a la población civil; c) la prensa de partido, que pudo transmitir las consignas de los partidos políticos más influentes; d) la radio, que tuvo informado simultáneamente a los frentes con la retaguardia a través de partes de guerra o programas musicales, que dulcificaron el ambiente bélico y consiguieron olvidar la espiral de la guerra.

Asimismo, pudimos comprobar, en muchos de los dibujos del universo, la intervención del maestro en la escena dibujada; y esto también se ha hecho evidente en los dibujos de María Antolín y Tomás. La niña copió de la pizarra el texto político. Y el niño calcó el vendedor o le ayudó el profesor, porque con 10 años de edad resulta sorprendente que lo reprodujera de memoria.

Además, destacamos que, durante la Guerra Civil, la venta callejera de la prensa fue el medio de difusión más utilizado que la suscripción.

También los niños reflejaron en sus dibujos la discriminación de género relacionada con los medios de comunicación. Magdalena representa a su padre sentado y leyendo el periódico, mientras las mujeres hacían las tareas del hogar. Victoriano, por su parte, dibuja un señor bien vestido, con sombrero y bastón, comprando el periódico. Tan solo Inés dibuja una miliciana leyendo en voz alta un periódico de trinchera a sus compañeras; pero al dibujar esta escena, la niña no se dio cuenta de que: a) refleja el 
alto nivel de analfabetismo existente entre los adultos de esa época; b) la figura de la mujer lectora se convierte en un instrumento más de propaganda por estar adoctrinando a las otras milicianas; c) la presencia del sexo femenino en el frente aumentó la moral de combate en los hombres.

Después de estas afirmaciones, sostenemos que estos cinco dibujos son retratos mentales infantiles tan válidos y reales como las fotografías que obtuvieron los reporteros de guerra nacionales e internacionales. Pretendemos homenajear con este escrito a los niños españoles, sin distinción de bandos, que fueron absorbidos por la espiral de la guerra y que fueron víctimas inocentes de esta conflagración.

\section{Referencias bibliográficas}

ALONSO, Jesús Javier (1998): 1937. Los niños vascos evacuados a Francia y Bélgica. Historia y memoria de un éxodo infantil, 1936-1940. Bilbao, Asociación de Niños Evacuados el 37.

ÁLVAREZ, Leandro \& FERNÁNDEZ, María del Carmen (2009): "El Liberal, de Sevilla (1901-1936). Un diario independiente en la Andalucía anterior a la Guerra Civil". Pasado y Memoria. Revista de Historia Contemporánea, número 8. Alicante, Servicio de Publicaciones de la Universidad de Alicante, pp. 199-220.

BEEVOR, Antony (2011): La guerra civil española. Barcelona, Crítica S. L.

BRUNER, Alfred (1946): Les répercussions psychiques de la guerre moderne sur l'enfance (Thèse de doctorat). Paris, Sorbona, Faculté des Lettres de l'Université de Paris.

CERVERA, Javier (1998): "La radio: un arma más de la Guerra Civil en Madrid". Historia y Comunicación Social, número 3. Madrid, Servicio de Publicaciones de la Universidad Complutense, pp. 263-293.

CHECA, Antonio (1989): Prensa y partidos políticos durante la II República. Salamanca, Ediciones Universidad de Salamanca.

DE LA OSSA, Marco Antonio (2011): La música en la guerra civil española. Cuenca, Universidad de Castilla-La Mancha. Facultad de Bellas Artes de Cuenca.

DE LAS HERAS, Beatriz (2009): Imágenes de una ciudad sitiada: Madrid (19361939). Madrid, Ediciones JC Clementine.

EUWEMA, Mathijs, DE GRAAFF, Donatien, DE JAGER, Ans \& KALKSMA-VANLITH, Brechtje (2008): "Research with children in war-affected áreas", en CHRISTENSEN, Pia \& JAMES, Allison: Research with children perspectives and practices. New York, Routledge, pp. 189-204.

FERNÁNDEZ, Juan Manuel (1990): "Medios de comunicación y extensión cultural en el Ejército republicano", en GARITAONAINDÍA, Carmelo; DE LA GRANJA, José Luis; \& DE PABLO, Santiago: Comunicación, cultura y política durante la II República y la Guerra Civil. Tomo II España (1931-1939). Bilbao, Servicio Editorial de la Universidad del País Vasco, pp. 376-401. 
GALLARDO, José Antonio (2012): El dibujo infantil de la evacuación durante la Guerra Civil española (1936-1939). Málaga, Servicio de Publicaciones de la Universidad de Málaga, SPICUM.

GALLARDO, José Antonio \& GALLARDO, Eva Margarita (2011): "La música dibujada por niños durante la Guerra Civil española (1936-1939)". Música y Educación, número 85. Madrid, Musicalis, S. A., pp. 78-105, en: http://www.albavolunteer.org/wp-content/uploads/2011/06/03.GUERRA-Y-MÚSICA.pdf [(Abraham Lincoln Brigades Archives, ALBA, New York), 9 de mayo de 2013]

GARCÍA, Beatriz (2011): “Cronología 1879-2011”, en MORAL, Enrique; ORTUÑO, Manuel; \& GARCÍA, Mercedes: El Socialista, 1886-2011. Prensa y compromiso político. Madrid, Editorial Fundación Pablo Iglesias, pp. 208-230.

GARITAONAINDÍA, Carmelo (1988): La radio en España (1923-1939): de altavoz musical a arma de propaganda. Madrid, Siglo XXI.

GONZÁLEZ, Carmen (1996): "Sociedad y Guerra: Condiciones de vida en la retaguardia murciana, a través del análisis de la prensa 1936-1939". Anales de Historia Contemporánea, número 12. Murcia, Servicio de Publicaciones de la Universidad de Murcia, pp. 471-481. http://revistas.um.es/analeshc/article /view/88211 [12-07-2013].

GONZÁLEZ, Eduardo (1990): "La prensa falangista y la prensa del Movimiento y del Estado: consideraciones sobre su origen y su desarrollo", en GARITAONAINDÍA, Carmelo; DE LA GRANJA, José Luis; \& DE PABLO, Santiago: Comunicación, cultura y politica durante la II República y la Guerra Civil. Tomo II España (1931-1939). Bilbao, Servicio Editorial de la Universidad del País Vasco, pp. 495517.

GUTIÉRREZ, Jesús (2007): La guerra civil en Eibar y Elgeta. Eibar, Eibarko Udala.

HERREROS, Mario (2007): "La actividad publicitaria barcelonesa durante la II República”, en CHECA, Antonio; ESPEJO, Carmen; LANGA, Concha; \& VÁZQUEZ, Miguel: La Comunicación durante la Segunda República y la Guerra Civil. Madrid, Editorial Fragua, pp. 176-203.

LÓPEZ SALAS, José Luis; SAN PEDRO, Juan Carlos \& LÓPEZ MARTÍN, E. C. (1997): Instrumentos básicos para la iniciación a la investigación descriptiva en la expresión plástica: determinación de objetivos. Oviedo, Servicio de Publicaciones de la Universidad de Oviedo.

MACHÓN, Antonio (2009): Los dibujos de los niños. Génesis y naturaleza de la representación gráfica. Un estudio evolutivo. Madrid, Ediciones Cátedra.

NASH, Mary (1999): Rojas, las mujeres republicanas en la Guerra Civil. Madrid, Taurus.

NúÑEZ, Mirta (1992): La prensa de guerra en la zona republicana durante la Guerra Civil española. Tomos I, II y III. Madrid, Ediciones de la Torre. 
OTERO, Eugenio \& GARCÍA, María (2006): Las Misiones Pedagógicas 1931-1936. Madrid, Residencia de Estudiantes.

PELÁEZ, José Manuel \& OLIVER, Pedro (1996): "La prensa de Albacete durante la Guerra Civil". AL-BASIT: Revista de Estudios Albacetenses, número 39 bis. Albacete, Servicio de Publicaciones de la Universidad de Albacete, pp. 51-58, en: http://dialnet.unirioja.es/servlet/articulo?codigo=1327168 [27-06-2013].

PERAL, Emilio (2012): “"Altavoz del frente». Una experiencia multidisciplinar durante la Guerra Civil española". Hispanic Research Journal: Iberian and Latin American Studies, (Vol. 13), núm. 3. London, University of London, pp. 234-249, en: http://dx.doi.org/10.1179/1468273712Z.00000000013

PIÑEIRO, María Teresa (2007): “A las mujeres. Las republicanas en las canciones de la Guerra Civill, en La Comunicación durante la Segunda República y la Guerra Civil, en CHECA, Antonio; ESPEJO, Carmen; LANGA, Concha; \& VÁZQUEZ, Miguel: La Comunicación durante la Segunda República y la Guerra Civil. Madrid, Editorial Fragua, pp. 530-540.

PIZARROSO, Alejandro (1990): "La propaganda del «Corpo Truppe Volontaire» (algunos aspectos de la intervención propagandística italiana en torno a la Guerra Civil española", en GARITAONAINDİA, Carmelo; DE LA GRANJA, José Luis; \& DE PABLO, Santiago: Comunicación, cultura y política durante la II República y la Guerra Civil. Tomo II España (1931-1939). Bilbao, Servicio Editorial de la Universidad del País Vasco, pp. 442-459.

PIZARROSO, Alejandro (2005): "La Guerra Civil española, un hito en la historia de la propaganda". El Argonauta Español, núm. 2. Marseille, France, Aix-Marseille Université, en: http://argonauta.imageson.org/document62.html [(23-04-2013].

SEOANE, María Cruz \& SAIZ, María Dolores (1998): Historia del periodismo en España. Tomo 3. El siglo XX: 1898-1936. Madrid, Alianza Editorial.

SEDEÑO, Ana María (2007): "El cartel publicitario como instrumento de estudio de género: la representación del papel femenino en la II República”, en CHECA, Antonio; ESPEJO, Carmen; LANGA, Concha; \& VÁZQUEZ, Miguel: La Comunicación durante la Segunda República y la Guerra Civil. Madrid, Editorial Fragua, pp. 530-540.

SIERRA, Verónica (2009): Palabras huérfanas. Los niños y la Guerra Civil. Madrid, Santillana Ediciones Generales, S. L.

SOLÉ i SABATÉ, Josep Maria \& VILLARROYA, Joan (2003): La España en llamas. La guerra civil desde el aire. Madrid, Ediciones Temas de Hoy.

THOMAS, Hugh (1976): La guerra civil española II. Barcelona, Grijalbo.

VEALE, Angela (2005): "Creative methodologies in participatory research with children”, en GREENE, Sheila \& HOGAN, Diane: Researching children's experience. London, Sage, pp. 253-272.

VENTÍN, José Augusto (1984): La radio en la Guerra Civil española (zona franquista) (Tesis doctoral. Tomo II). Madrid, Editorial de la Universidad Complutense. 
WEISSBERGER, Joseph Anthony (1938): The Still Draw Pictures! A collection of 60 drawings made by Spanish Children during the war. New York, Spanish Child Welfare Association of America for the American Friends Service Committee.

ZARAGOZA, Luis (2007): "Canciones para una guerra: la propaganda republicana a través de la música durante la Guerra Civil española", en CHECA, Antonio; ESPEJO, Carmen; LANGA, Concha; \& VÁZQUEZ, Miguel: La Comunicación durante la Segunda República y la Guerra Civil. Madrid, Editorial Fragua, pp. 485-501. 